\title{
¿Qué legión IV reclutó Alejandro Severo?
}

\author{
Bartomeu Celià Sastre *
}

\begin{abstract}
RESUMEN
ABSTRACT

Según la Historia Augusta, Alejandro

According to Historia Augusta,

Severo reclutó una legión, a la que Alexander Severus recruited a legion, otorgó el numeral IV. Esta legión ha sido identificada por varios investigadores como la IV ITALICA. Este artículo trata sobre la posibilidad de que el apelativo no sea el de ITALICA, sino otro, concretamente el de PARTHICA. to which he gave the number $\mathrm{IV}$. This legion has been identified by several scholars as IV ITALICA. This paper deals with the possibility that the name is not ITALICA, but another, in particular as PARTICA.
\end{abstract}

En el año 221 Ardashir (Artajerjes), miembro de la casta sacerdotal de Persépolis, se pronunció frente a Artabano $V$, rey de los partos, $y$, tras aglutinar las diferentes facciones de las regiones persas, estalló la guerra civil. Ésta terminó en el 227 con la muerte de Artabano y la fundación del nuevo Imperio Persa, gobernado por el propio Ardashir.

Los primeros roces con los romanos tuvieron lugar cuando Ardashir intentó intervenir en Armenia, territorio de influencia romana y desde donde había actuado Artavasdes, hijo de Artabano, que pretendía organizar la resistencia frente al nuevo poder persa, aunque pronto fue capturado y ejecutado.

En el 230 Ardashir se sintió aún más fuerte y con el pretexto de querer reinstaurar el antiguo Imperio Aqueménida, del cual se sentía heredero

Profesor de E.S. CEPA. Son Canals. 
legítimo, sus tropas invadieron Mesopotamia, entrando en territorio romano y pusieron cerco a Nisibis ${ }^{1}$. Entretanto, otros contingentes persas amenazaban Siria y Capadocia.

Las fronteras romanas en Oriente habían estado tranquilas desde la subida al poder de Heliogábalo en el 218 y la naturaleza del ataque, con un enemigo nuevo, agresivo, de ambiciones expansionistas y que cerraba las puertas a cualquier negociación ${ }^{2}$, no dejaba al entonces emperador, Alejandro Severo, más opción que una respuesta militar.

Las fuentes ${ }^{3}$ informan del desplazamiento de contingentes del Rhin y del Danubio hacia Oriente, debilitándose la presencia militar en aquellos frentes. Además se hicieron levas en la misma Italia y en otros territorios romanos ${ }^{4}$. En el 231 el propio Alejandro Severo marchó a dirigir la campaña, saliendo de Roma con un contingente de pretorianos y, seguramente, la legión II PARTHICA, de guarnición en Castra Albana, cerca de la capital ${ }^{5}$. Ya en Oriente, estableció su cuartel general en Antioquía, donde tuvo que hacer frente a los disturbios provocados por los soldados de las legiones procedentes de Siria y Egipto, que se lamentaban del exceso de disciplina impuesto, pretendiendo incluso un cambio de emperador ${ }^{6}$. Tras sofocar el motín, la reacción de Alejandro fue disolver alguna legión. Sin embargo, la rehabilitó a los treinta días, justo antes de empezar la campaña ${ }^{7}$.

El plan de ofensiva romano consistía en un ataque coordinado de tres ejércitos por tres frentes separados, invadiendo el territorio persa y convergiendo seguramente en Ctesifonte, la antigua capital de los partos. La primera columna invadiría Media a través de Armenia. Por el sur, otro ejército entraría en las regiones occidentales persas, mientras que el propio Alejandro Severo, con el grueso del ejército, forzaría la entrada por el centro ${ }^{8}$.

\section{HER VI 2,1.}

2 HER VI 4, 5 . Ardashir llegó a reclamar a los romanos todas sus provincias orientales.

3. Por ejemplo Herodiano VI 3, 1-2; VI 4, 7 y VI 7, 3. J. Rodriguez (Evolución histórica de las legiones del Imperio romano [tesis doctoral mecanografiada], Valladolid, 1997) da una lista de legiones que intervinieron en la campaña: del Rhin marcharon vexillationes de las legiones $|\mathrm{M}|$ NERVIA, VIII AUGUSTA y XXII PRIMIGENIA y seguramente la XXX ULPIA estuvo al completo. De las legiones del Danubio, vexillationes de las legiones I ITALICA, II ADIUTRIX, II ITALICA, III ITALICA, IV FLAVIA, VII CLAUDIA, X GEMINA Y XIV GEMINA, además de las I ADIUTRIX y XI CLAUDIA al completo. A esta lista hay que añadir unidades procedentes de Africa, Hispania y otras de recluta reciente, aparte del ejército de las provincias orientales.

${ }^{4}$ HER. VI 3,$1 ;$ ILS 1.173

5 HER VI 3,2 a VI 4, 1 . Alli se habla exclusivamente de la guarnición de Roma.

6 HER. VI 4, 7; S.H.A. Alejandro Severo 53

S.H.A. Alejandro Severo 54; J. Rodriguez (Evolución..., op. cit. págs. 205 y 416) cree que la legión disuelta pudo ser la IV SCYTHICA o la XVI FL.AVIA. 
Esta última columna debía estar formada por seis legiones, los falangiarios, como el emperador los llamaba, tratando de imitar la forma de la antigua Falange macedónica ${ }^{9}$.

En la fase inicial, sólamente el ejército del norte tuvo éxito, consiguiendo alcanzar sus objetivos. El que operaba en el sur, sin embargo, sufrió una derrota completa ${ }^{10}$, mientras que el contingente al mando del propio emperador fue afectado por una epidemia y tuvo que replegarse ${ }^{11}$. En ese momento falló la coordinación entre las tres columnas. Sin apoyo, el ejército del norte se enfrentó a una retirada hacia sus bases y a causa de los rigores del invierno sufrió enormes pérdidas ${ }^{12}$.

De nuevo en Antioquía, Alejandro Severo planeó una nueva campaña que no llegó a realizarse debido a las noticias que le llegaron sobre invasiones bárbaras en las zonas del Rhin y del Danubio, en aquel momento escasamente protegidas ${ }^{13}$. Ello le obligó a volver a Europa, aunque antes de marchar al norte pasó por Roma (año 233) donde celebró un Triunfo ${ }^{14}$ en el cual fue aclamado como INVICTUS, PARTHICUS y PERSICUS ${ }^{15}$, siendo este un título nuevo, jamás ostentado antes por un emperador romano. Curiosamente, la guerra con los persas no terminó con ningún tratado de paz, sino con la retirada de cada uno de los dos bandos tras sus respectivas fronteras ${ }^{16}$. El hecho de la celebración de un Triunfo se debió a la necesidad política del propio Alejandro Severo de celebrar una victoria, aunque las ventajas obtenidas en la campaña habian sido nulas, salvo la de que los persas no consiguieran su objetivo de conquista de todo el Oriente romano. Algunas fuentes ${ }^{17}$, sin embargo, aseguran que Alejandro consiguió una gran victoria sobre los persas. Para ello se basan, sin duda, en la celebración del mencionado Triunfo.

HER. VI 5, 1-2.

S.H.A. Alejandro Severo $50,5$.

Herodiano (VI 5, 7-10) habla de aniquilación.

Herodiano (VI 6, 2) habla en este pasaje sólamente de la enfermedad sufrida por el emperador, pero otra interpretación del asunto es que tal enfermedad fue en realidad una epidemia sufrida por el ejército, máxime cuando poco después $(V \mid 6,3)$ dice que hubo pérdidas por enfermedad.

HER. VI $6,3$.

HER. VI 7, 2-3; S.H.A. Alejandro Severo 59, 2.

S.H.A. Alejandro Severo $56,1$.

5 S.H.A. Alejandro Severo 56, 9; Roldán, J.M., BlázQuez, J. y Del Castillo, A.: Historia de Roma, Vol. II. Madrid, 1989. pág. 264.

HER. VI 6, 4-6.

17 S.H.A. Alejandro Severo 55 a 57, 1; OROSIO Hist. VII 18, 7; AURELIO VÍCTOR Caes. XXIV; EUTROPIO Brev. VIII 23. 
Tras dirigirse a Germania estableció su cuartel general en Mogontiacum, siendo asesinado en un motín en la actual Bretzenheim, cerca de Mainz, el 21 ó 22 de marzo del 235. Hay confusión en las fuentes a la hora de establecer el lugar de su muerte ${ }^{18}$, diciendo algunas que fue en Britania. La confusión podría deberse a la presencia en el lugar de una unidad de auxiliares britanos. En esta sedición militar jugaron un papel destacado las fuerzas que estaban al mando de Maximino, uno de sus mejores generales y luego su sucesor ${ }^{19}$. Según la Historia Augusta ${ }^{20}$, Alejandro Severo había formado una nueva legión, la IV, a cuyo mando había puesto al propio Maximino para que instruyera a los nuevos reclutas. Se puede suponer que tal legión pudo formarse en el 231 estando relacionada con los reclutamientos realizados en vistas a la campaña en Oriente.

El hecho es que en el período comprendido entre los imperios de Adriano y Heliogábalo, un siglo aproximadamente, sólo se habían reclutado cinco nuevas legiones. Marco Aurelio reclutó dos, las II y III ITALICAE en el año 168 para utilizarlas en sus campañas contra los marcomanos. Su apelativo venía a causa del origen italiano de sus primeros reclutas ${ }^{21}$, mientras que los numerales eran para continuar la serie de la I ITALICA, formada por Nerón con reclutas italianos en el año 67. Las II y III ITALICAE fueron posteriormente destinadas a la frontera del Danubio, teniendo sus campamentos permanentes la II en Lauriacum (Nórico) y la III en Castra Regina (Recia). En el año 196 Septimio Severo reclutó tres nuevas legiones para utilizarlas en su campaña contra los partos, llamándolas I, II y III PAFTHICAE. De ellas, la I y la III fueron posteriormente destinadas a la provincia de Mesopotamia, mientras que la II tuvo su base permanente durante todo el siglo III en Italia. No se conoce ningún otro caso de reclutamiento de una nueva legión hasta el año 231, aunque es posible que Caracalla pensara en algo semejante ${ }^{22}$.

${ }_{18}$ Orosio (Hist. VII 18, 8) fija su muerte en Mogontiacum; Eutropio (Brev. VIII 23) en la Galia; Aurelio Víctor (Caes. XXIV) en Britania y en S.H.A. (Alejandro Severo 59, 6) se recogen las dos últimas tradiciones.

19 No se conoce con precisión el cargo que ocupaba Maximino en el momento de la muerte de Alejandro Severo. En el año 231 era el responsable de la instrucción de los nuevos reclutas (praefectus tironibus) para posteriormente recibir el mando de una legión. Según J. RodRiguez ("Las carreras militares de los emperadores romanos antes de acceder al trono. II: la Anarquía Militar y el siglo IV (235-395)", Hispania Antiqua XX, 1996, pág. 369), después de la campaña contra los persas fue nombrado gobernador de Niesopotamia. En el 235 estaba en Europa combatiendo a los germanos, quizá con el cargo de gobernador de una provincia fronteriza. Aurelio Víctor (Caes. XXV) afirma que era gobernador de Trebellica.

20 S.H.A. Los dos Maximinos $5,5$.

21 LiBeRATI, A. y SiLVERIO, F: Organizzazione militare: esercito, Roma, 1989. págs. 77 y 79 ; Rodríguez, J.: Evolución..., op. cit. págs. 107 y 168.

22 HER. IV 8, 2; S.H.A. Antonino Caracalla 6, 2-3. 
Respecto a la legión reclutada por Alejandro Severo, hasta los años veinte de este siglo, la mayor parte de los investigadores pensaban que Alejandro Severo no hizo tal cosa sino que, en todo caso, aumentó los efectivos de las unidades disponibles. D. Magie ${ }^{23}$ afirmó que esa legión IV era la IV FLAVIA, que ya existía desde los tiempos de Vespasiano y estaba acuartelada en Mesia Superior. El único dato disponible sobre la legión reclutada por Alejandro Severo, aparte de su numeral IV es que Maximino había sido su comandante ${ }^{24}$. En 1923 E.C. von Nischer ${ }^{25}$ suponía, sin aportar el más mínimo dato, que tal legión era la I IULIA ALEXANDRIA, dejando de lado el numeral IV. De tal legión no se sabe demasiado, sólamente que en el siglo $V$ tenía el rango de COMITATENSE y que estaba destinada en la diócesis de Tracia ${ }^{26}$. Sin embargo, ya por aquellos años fueron prevaleciendo las ideas de E. Ritterling ${ }^{27}$ y H.M.D. Parker ${ }^{23}$ que pensaban que la legión reclutada por Alejandro Severo era la IV ITALICA. Tampoco se sabe demasiado, por no decir casi nada, de esta unidad. En la Notitia Dignitalum ${ }^{29}$ aparece reseñada como PSEUDOCOMITATENSE, por tanto sin campamento fijo, a disposición del Magister Militum per Orientem. A.J. Reinach ${ }^{30}$ le atribuye como emblemas la cigüeña y el centauro, basándose en la interpretación de una moneda de Galieno. También se suele relacionar esta legión con un pasaje de la Historia Augusta ${ }^{31}$, donde se menciona a un tal Serapamón como comandante de una legión IV en tiempos de Gordiano III. El nombre de Serapamón no parece propio de un ciudadano romano, sino de un egipcio, aunque indudablemente poseía la ciudadanía desde que el año 212 la Constitutio Antoniniana se la otorgó a todos los habitantes libres del Imperio. Además sólo es conocido en la Historia Augusta y puede ser una invención del autor, como otras muchas que aparecen en esa obra. Por otra parte, la relación entre el mando de esa legión IV y la IV ITALICA es pura especulación.

23 Magie, D.: The Scriptores Historiae Augustae, London, 1921. Vol.ll, pág. 323, nota 2.

24 S.H.A. Los dos Maximinos 5.5.

25 NisCHER, E.C. von: "The Army Reforms of Diocletian and Constantine and their Modifications up to the Time of the Notitia Dignitatum», JRS XIII, 1923, págs. 1 y 2.

26 N.D. Or. VIII 51. Hay que destacar que en este documento aparece sin numeral. No sería descartable, sin embargo, que originariamente lo portara y que por alguna razón desconocida lo hubiese perdido.

27 Ritterling, E.: “Legio», en RE XII, cols. 1326, 1.549.

28 PARKER, H.M.D.: «The Legions of Diocletian and Constantine», JRS XXIII, 1933, pág. 176.

29 N.D. Or. VII 54

30 REINACH, A.J.: «Signa militaria», en DSIV/2, pág. 1.311.

31 S.H.A. Los tres Gordianos 25,2 . Esta relación la establece RITTERLING, E.: «Legio», op. cit. col. 1337 
Es destacable también el hecho de que no se conozca campamento fijo para la IV ITALICA durante el siglo III. E.C. von Nischer ${ }^{32}$, que suponía que esta legión había sido reclutada en tiempos de la Tetrarquía, expuso una teoría según la cual la provincia en la que estaba destinada era la de Secuania. Sugirió que si las legiones del Nórico eran entonces la I NORICORUM y la II ITALICA y la de Recia la III ITALICA, entonces en Secuania, la siguiente provincia, debía haber, para seguir la serie, una legión IV, y estudiando todos los casos dedujo que se trataba de la IV ITALICA.

Por otra parte, resulta raro que Alejandro Severo concediera a la legión que reclutó el apelativo de ITALICA ya que en ella, aparte de itálicos había una gran proporción de reclutas panonios e ilíricos ${ }^{33}$. La única posibilidad sería que él, al meditar sobre el numeral y el apelativo que otorgaría a su legión, recordara a Marco Aurelio e intentara vincularse con él. Esto tiene sentido, pues cuando llegó al poder cambió el que era su nombre original, Alexianus ${ }^{34}$ y/o Basianus ${ }^{35}$ por el de Marcus Aurelius Severus Alexander, con el fin de vincularse a los Antoninos y a los Severos. Hay que reseñar, sin embargo, que todos los emperadores de la dinastía Severa se habían hecho llamar Antoninus por conveniencias políticas.

De lo expuesto anteriormente se deduce que Alejandro Severo, aunque tenía algunos motivos como para otorgar a su legión IV el apelativo de ITALICA, éstos eran de escaso peso. Además no queda registrada la existencia de la IV ITALICA durante los años de su gobierno. Los indicios sobre esta unidad durante la Anarquía Militar son también demasiado débiles como para ser tenidos en cuenta. Podemos así casi concluir que la legión IV ITALICA puede ser perfectamente de la época de la Tetrarquía pues no hay evidencias sólidas que revelen su existencia en una época anterior a ésta. Así, la tesis ya mencionada de E.C. von Nischer sobre su ubicación en Secuania no carece de sentido y debe ser tomada en cuenta.

En mi opinión, si Alejandro Severo otorgó a su legión el numeral IV no fue para vincularla a las li y III ITALICAE sino a las I, II y III PARTHICAE, las últimas legiones reclutadas. Si esto es así, el nombre más lógico para tal legión es el de IV PARTHICA. Esta unidad existió realmente, pero se

\footnotetext{
32 NisCHER, E.C. von: “The Army Reforms...", op. cit. pág. 22. Esta teoría también aparece en Kromayer, J. y VEiTH, G.: Heerwessen und kriegsführung der Griechen und Römer, Munich, 1928, pág. 483 y mapa 54, ilustración 147.

${ }_{33}$ En HER. VI 7, 3 y VII 8, 11 se cuenta que en su campaña de Italia del 238, Maximino mandó por delante a las legiones panonias, en las que confiaba plenamente porque habían sido las primeras en proclamarle emperador (Cfr. también Rodriguez, J.: Evolución..., op. cit. pág. 188).

34 HER. $\vee 3,3$

35 DIÓN LXXIX 30, 3 y LXXX 18, 3.
} 
suele vincular su creación con la reorganización militar de Diocleciano ${ }^{36}$. En la Notitia Dignitatum ${ }^{37}$ aparece con la categoría de LIMITANEI, destinada en Circesium (Osroene). Hubo dos legiones más que llevaron el apelativo de PARTHICA: la V PARTHICA, legión que tenía su base en el siglo IV en Amida (Mesopotamia) y que fue destruida en la toma de la ciudad por los persas en el año $360^{38}$ y la VI PARTHICA, que en siglo $\mathrm{V}$ tenía la categoría de PSEUDOCOMITATENSE a disposición del Magister Militum per Orientem ${ }^{39}$.

Aunque desde el 227 el enemigo de Roma ya no era propiamente Partia sino el Imperio Persa, la mayor parte de los emperadores romanos del siglo III, desde Alejandro Severo hasta Carino, utilizaron las titulaciones de PARTHICUS y PERSICUS, en general las dos a la vez ${ }^{40}$, y aún en el siglo IV a los persas se les llamaba partos. Por ejemplo, el historiador Eutropio ${ }^{41}$, que participó en la campaña oriental de Juliano en el 363, llama a sus enemigos partos o persas, indistintamente, e igual situación vemos también en Aurelio Víctor ${ }^{42}$.

Sin embargo, a nivel oficial, a partir de Diocleciano se identificaba al rival oriental como los persas: Dioclecian o y sus colegas de Tetrarquía no utilizaron nunca la titulación de PARTHICUS, sino la de PERSICUS, y ninguno de sus sucesores volvió a usar la primera de ellas ${ }^{43}$. Por tanto, no tiene mucho sentido el que Diocleciano impusiera a algunas de sus nuevas legiones un apelativo derivado del nombre de un enemigo que ya no existía. Por otra parte, la teoría de que, por capricho, quisiera continuar la serie de legiones de la I a la III PARTHICAE hasta la VI PARTHICA resultaría un caso único que no tiene punto de comparación. Del mismo modo, en la diócesis de Panonia, donde estaban acuarteladas las I y || ADIUTRICES,

36 Nischer, E.C. von: “The Army Reforms...”, op. cit. pág. 3; PARKER, H.M.D.: “The Legions...», op. cit. pág. 178; Rodríguez, J.: Evolución..., op. cit. pág. 557

$37 \quad$ N.D. Or. $X X X \vee 24$

38 AMIANO XVIII 9, 3.

39 N.D. Or. VII $19=55$.

40 Filipo el Árabe ostentaba los títulos de PARTHICUS y PERSICUS; Valeriano acuñó monedas con la leyenda VICTORIA PARTHICA; Galieno llevó el título de PARTHICUS; Aureliano fue PARTHICUS y PERSICUS, al igual que Caro y sus hijos Numeriano y Carino.

41 EUTROPIO Brev. X 16 y VIII 23, por ejemplo.

42 Aurelio Victor, Caes. 24 y 33

43 Según T.D. Barnes («Imperial Campaigns A.D. 285-311», Phoenix 30, 1976, pág. 176), los títulos de los Tetrarcas fueron: GERMANICUS, SARMATICUS, PERSICUS, BRITANNICUS, CARPICUS, ARMENICUS, MEDICUS y ADIABENICUS. Según P. Batlle (Epigrafia latina, BarceIona, 1963, págs. 132, 133), Constantino utilizó los de GERMANICUS, GOTHICUS, ARMENIACUS, CARPICUS, SARMATICUS, MEDICUS, BRITANNICUS, ARABICUS y PERSICUS y Constancio II los de GERMANICUS, ALAMANNICUS, GOTHICUS, SARMATICUS, ADIABENICUS Y PERSICUS. 
en campos relativamente cercanos, reclutó algunas legiones, pero ninguna de ellas fue llamada la III ADIUTRIX ${ }^{44}$. Por último, cabe destacar que se desconoce la ubicación de las legiones III, V y VI PARTHICAE a comienzos del siglo IV. Incluso es posible que la III PARTHICA ya no existiese, habiendo sido destruida durante alguna campaña del siglo III ${ }^{45}$.

Por lo que respecta al origen de las legiones $V$ y VI PARTHICAE, no es descartable, aunque no haya referencias que lo corroboren, que hubiesen sido reclutadas en tiempos de la Anarquía Militar, cuando el título de PARTHICUS estaba todavía vigente, quizás por obra de Aureliano, que formó algunas legiones ${ }^{46}$, o incluso existe la posibilidad, aunque mínima, de remontarse al propio Alejandro Severo y suponer que las seis legiones PARTHICAE fueran las seis legiones que utilizó que utilizó formando una falange al estilo macedónico durante su guerra persa ${ }^{47}$.

El hecho de no haberse encontrado documentación sobre la IV PARTHICA o el lugar de su campamento permanente durante los tiempos de la Anarquía Militar no es condición suficiente para pensar que no existiese en esa época. En ese período se carece de información sobre muchas legiones. Este comentario puede hacerse extensivo al caso de las legiones $V$ y VI PARTHICAE.

Después de todo lo dicho, se pueden extraer una serie de conclusiones finales:

1. No existen datos concluyentes que hagan suponer que Alejandro Severo reclutara la legión IV ITALICA.

2. De la mencionada IV ITALICA no se conoce prácticamente nada.

3. El motivo más lógico por el que Alejandro Severo otorgó el numeral IV a la legión que reclutó en el año 231 no es otro que el seguir la serie de las tres últimas legiones formadas, las I, II y III PARTHICAE, en el 196 por Septimio Severo.

44 La Panonia Inferior, donde se acuartelaban las I y II ADIUTRICES, fue dividida en Panonia II y Valeria. En esta última quedaron dichas unidades como fuerza legionaria, mientras que en la Panonia II se situaron dos legiones nuevas, la V IOVIA y la VI HERCULIA, aunque los campamentos de estas cuatro legiones estaban relativamente cercanos

45 LiBeRATI, A. y Sil.verio, F.: Organizzazione..., op. cit. pág. 79. De la legión ill PARTHICA no hay datos durante la segunda mitad del siglo lli y además no aparece en las listas de la Notitia Dignitatum. J. Rodriguez (Evolución..., op. cit. pág. 177) da crédito a la posibilidad de que existiese incluso en el siglo $V$ y que el hecho de que no aparezca en la Notitia es porque su nombre debía estar en uno de los trozos deteriorados.

46 A Aureliano se le atribuye el reclutamiento de dos legiones en Oriente, la I ILLYRICORUM y la IV MARTIA.

47 S.H.A. Alejandro Severo, 50,5. 
4. Siguiendo ese razonamiento, tal legión reclutada sería la IV PARTHICA.

5. El hecho de que no se disponga de información sobre la existencia de esta legión hasta la época de Diocleciano no implica su inexistencia en tiempos anteriores: hay una gran escasez de datos (con respecto a otras épocas) sobre las unidades militares romanas en el siglo III.

6. Existe un alto grado de posibilidad de que también las legiones $V$ y VI PARTHICAE fueran formadas en tiempos anteriores a la llegada la poder de Diocleciano. 